Unpublished reports indicate that stigma contributes to only a few health workers opting to take psychiatry and psychiatric nursing as a discipline for specialisation.

\section{Training}

The Institute of Health Services, Lobatse campus, runs an 18-month Diploma in Advanced Community Mental Health Nursing course. The University of Botswana opened its School of Medicine in August 2009 with the intake of the first MBBS undergraduates. It is on schedule to establish a 400-bed academic hospital in Gaborone. Psychiatry will be offered as a modular course for the undergraduates and will be allocated one month of study on the postgraduate course in family medicine (see http://www.ub.bw).

\section{Mental health disorders}

According to the annual reports of the Lobatse Mental Hospital and Jubilee Psychiatric Unit for the years 2005-08, the five conditions most commonly presenting in the inpatient unit were:

1 schizophrenia

2 depressive disorders

3 alcohol use disorders

4 bipolar affective disorders

5 epilepsy.

In the out-patient unit they were:

1 schizophrenia

2 cannabis-induced disorders

3 depressive disorders

4 alcohol use disorders

5 epilepsy.

\section{Mental health legislation}

The current law was enacted in 1971 (5 years after independence) and is due to be reviewed and updated.

\section{Mental health policy}

The July 2003 Botswana National Policy on Mental Health provides a framework for the incorporation of the objectives of the mental health programme into the existing general health services. The aim of the policy is to provide access to services, to enable every individual to have the benefit of good mental health and thus allow them to make an optimal contribution to personal, community and national development.

\section{The future of mental health services}

As in the USA (Bernstein et al, 2010), although society's perception of individuals with mental illness has improved, stigma is still significant in Botswana. With the opening of Sbrana Psychiatric Hospital, there is hope that the facility will be accredited along with other major general hospitals by the Council for Health Service Accreditation of Southern Africa (COHSASA) as meeting international standards.

\section{Sources}

Bernstein, C. A., Hershfield, B. \& Cohen, D. C. (2010) Psychiatry in the USA: an overview. International Psychiatry, 7, 90-92.

World Health Organization (2009) World Health Statistics. WHO. At http://www.who.int/countries/bw/en (accessed January 2011).

\title{
Criteria for compulsory admission in some European countries
}

\section{A. Carballedo ${ }^{1}$ and M. Doyle ${ }^{2}$}

1Senior Registrar in Psychiatry, Cheeverstown House, Dublin, Ireland, email carbala@tcd.ie; ${ }^{2}$ Registrar in Psychiatry, St James Hospital, Dublin, Ireland

\begin{abstract}
Compulsory admission to mental health facilities is a controversial topic, as it impinges on personal liberty and the right to choose, and it carries the risk of abuse for political, social and other reasons (Gostin, 2000). However, involuntary admission can prevent harm to self and others, and assist people in attaining their right to health, which, due to their mental disorder, they are unable to manage voluntarily. Since the 1950s and 1960s, the delivery of mental health has shifted from a paternalistic emphasis on the need to treat those who are not able to look after themselves, to the rights of patients who have a mental illness. The Principles for the Protection of Persons with Mental
\end{abstract}

Illness ('the MI Principles') adopted by the United Nations in 1991 play an important role in raising awareness about the human rights of people with mental health problems. They provide guidance on areas such as the procedures for involuntary admission to mental health facilities and standards of care (Knapp et al, 2007). Legal frameworks for involuntary placement of those who are mentally ill have been reformed in many European countries. Most regulate compulsory admission and treatment by special mental health laws. Only Greece, Spain, Italy and those member states of the European Union (EU) that joined in 2004 and 2007 have no separate laws (Dressing \& Salize, 2004). 
Increasing rates of compulsory admission have been reported by some authors (e.g. Darsow-Schutte \& Muller, 2001). However, comparison of the time series of compulsory admission quotas during the past decade reveals a slightly more homogeneous pattern, with more or less stable quotas in most countries (Salize \& Dressing, 2004). Some countries have made the focus of commitment laws the protection of society at large from people who are mentally ill, but this has led to a public perception of those with mental disorders as dangerous and thus contributes to their stigmatisation, when in fact more recent studies do not show a marked difference in the danger presented by those who are mentally ill and the general population (Swanson et al, 1990). Studies conclude though that in routine clinical practice the characteristics of compulsory admission are rather stable, irrespective of the various criteria for commitment. This suggests that decision-making procedures across the world rely on similar objective and 'good faith' criteria for involuntary placement (Appelbaum, 1997). It is important also to consider that the availability of alternatives that are more acceptable to patients might contribute to increasing or reducing the rates of compulsory admission in different countries.

Overviews of national approaches are scarce. There is a lack of sound studies in the field and statistics on compulsory admissions are rarely published internationally (Riecher-Rossler \& Rossler, 1993). Consequently, the European Commission funded in 2000 a study that gathered and analysed information on the differences and similarities of legal frameworks for the involuntary placement or treatment patients presenting with a mental illness across the EU member states, and the outcome in terms of involuntary admission rates to psychiatric facilities. Our paper aims to give a brief overview of compulsory admission data from official sources across some European countries through a review of the literature published to date in relation to this issue.

\section{Different criteria for different countries}

The Salize report in 2004 (Salize \& Dressing, 2004) highlighted that frequencies of compulsory admissions vary remarkably among countries in Europe. This finding was not surprising given the large differences in the relevant legal instruments, but it was astonishing given the much smaller differences in psychiatric morbidity. The authors of the Salize report concluded that involuntary admissions were a result of a complex set of still poorly understood legal, political, economic and social factors. A more recent European research initiative, the EUNOMIA project in 2005 (Kallert et al, 2005), carried out in 12 countries (Bulgaria, Czech Republic, England, Germany, Greece, Italy, Israel, Lithuania, Poland, Slovak Republic, Spain, Sweden), included the objective of providing detailed information on the basis of involuntary psychiatric admission.

To define clear conditions that have to be met when persons who are mentally ill should be involuntarily placed is crucial for preventing abuse. Although the laws of all countries studied stipulate a confirmed mental disorder as a major condition for detention, additional criteria are heterogeneous. Threatened or actual danger to oneself or to others is the most common additional criterion, but is not a prerequisite in Italy, Spain or Sweden, or in England, Wales or Scotland. Some other countries such as Denmark, Finland, Greece, Ireland and Portugal do stipulate as further criteria the need for treatment and danger. The other countries we considered in the review had as a further criterion danger on its own. Some countries emphasise a lack of insight on the part of the patient, additionally. No significant correlation could be identified with compulsory admission quotas or rates when comparing countries applying the 'danger' or 'need for treatment' criterion (Dressing \& Salize, 2004). Dangerousness is an additional criterion for involuntary psychiatric admission in Lithuania, Bulgaria, the Czech Republic, the Slovak Republic and Poland (Kallert et al, 2005) (Table 1).

In most countries studied, the final decision on involuntary placement is made by a non-medical authority, either a representative of the legal system (judge, prosecutor, mayor) or another agency independent of the medical system. In the remaining member states the decision is left to psychiatrists or other healthcare professionals (Table 1). However, it is important to mention that in all countries, thorough assessments are performed by psychiatrists as soon as a patient is admitted to a psychiatric facility (Dressing \& Salize, 2004; Kallert et al, 2005). According to the laws of six European countries, notification or inclusion in the procedure of a legal representative of the patient (e.g. advocate, counsellor or social worker) is mandatory. Countries with obligatory inclusion of a legal representative showed significantly lower compulsory admission quotas and a trend towards lower compulsory admission rates (Salize \& Dressing, 2004).

Across Europe, the legally stipulated period of time that may elapse between psychiatric assessment and the actual start of an involuntary placement ranges from 24 hours (in Luxemburg, Spain, Sweden, The Netherlands, Ireland, Bulgaria, Czech Republic and Slovak Republic) to 10 days (in Belgium). Emergency procedures for short-term placement are defined separately in some countries and are usually applied at night, weekends, or whenever immediate action is deemed necessary. Short-term detention usually is permitted from 24 to 72 hours (except in Belgium, where it is up to 10 days). There are also large differences with regard to the maximum length of a compulsory admission order. Only Denmark, France, Portugal and Spain do not define a maximum duration for initial involuntary placement. For the rest of the countries we have considered in the review, initial placements may vary from 7 days to 2 years (e.g. 7 days in Italy, 14 days in Luxembourg, 4 weeks in Sweden, 21 days in Ireland and up to 6 months in the UK). Other countries have lengthy initial placements, such as Austria, Bulgaria, the Slovak Republic and the Czech Republic, with 3 months; Poland, with 6 months; and Belgium and Germany, with up to 2 years. Reapproval or reassessment procedures are established in all countries studied (Salize \& Dressing, 2004; Kallert et al, 2005). For clarification see Table 1.

\section{The demographic characteristics of detained patients}

Research studies suggest that the largest group admitted involuntarily are people with severe and chronic mental disorders such as schizophrenia or other psychoses; they account for $30-50 \%$ of all involuntary placements in states 
Table 1

\begin{tabular}{|c|c|c|c|c|c|}
\hline Country & $\begin{array}{l}\text { Essential legal criteria for } \\
\text { detention (additional to } \\
\text { mental disorder) }\end{array}$ & $\begin{array}{l}\text { Deciding authority } \\
\text { for detention order }\end{array}$ & $\begin{array}{l}\text { Mandatory } \\
\text { inclusion of } \\
\text { patient counsel }\end{array}$ & $\begin{array}{l}\text { Detention for } \\
\text { assessment }\end{array}$ & $\begin{array}{l}\text { Maximum length of } \\
\text { initial placement }\end{array}$ \\
\hline${ }^{1}$ Austria & Danger & Non-medical & Yes & 48 hours & 3 months \\
\hline${ }^{1}$ Belgium & Danger & Non-medical & Yes & 10 days & 40 days to 2 years \\
\hline${ }^{1}$ Denmark & $\begin{array}{l}\text { Danger or need for } \\
\text { treatment }\end{array}$ & Medical & Yes & $\begin{array}{l}\text { Not separately } \\
\text { defined }\end{array}$ & Not defined \\
\hline${ }^{1}$ Finland & $\begin{array}{l}\text { Danger or need for } \\
\text { treatment }\end{array}$ & Medical & No & $\begin{array}{l}\text { Not separately } \\
\text { defined }\end{array}$ & 9 months \\
\hline${ }^{1}$ France & Danger & Non-medical & No & 48 hours & Not defined \\
\hline${ }^{1}$ Germany & Danger & Non-medical & No & 24 hours to 3 days & 6 weeks to 2 years \\
\hline${ }^{1}$ Greece & $\begin{array}{l}\text { Danger or need for } \\
\text { treatment }\end{array}$ & Non-medical & No & 48 hours & 6 months \\
\hline${ }^{1}$ Ireland & $\begin{array}{l}\text { Danger or need for } \\
\text { treatment }\end{array}$ & Medical & Yes & $\begin{array}{l}\text { Not separately } \\
\text { defined }\end{array}$ & 21 days \\
\hline${ }^{1}$ Italy & Need for treatment & Non-medical & No & 48 hours & 7 days \\
\hline${ }^{1}$ Luxembourg & Danger & Medical & No & 24 hours & 14 days \\
\hline${ }^{1}$ Netherlands & Danger & Non-medical & Yes & 24 hours & 3 weeks to 12 months \\
\hline${ }^{1}$ Portugal & $\begin{array}{l}\text { Danger or need for } \\
\text { treatment }\end{array}$ & Non-medical & Yes & 48 hours & Not defined \\
\hline${ }^{1}$ Spain & Need for treatment & Non-medical & No & 24 hours & Not defined \\
\hline 'Sweden & Need for treatment & Medical & No & 24 hours & 4 weeks \\
\hline${ }^{1} \mathrm{UK}$ & Need for treatment & $\begin{array}{l}\text { Non-medical and } \\
\text { medical }\end{array}$ & No & 72 hours & 28 days to 6 months \\
\hline${ }^{2}$ Bulgaria & Danger & Non-medical & No & 24 to 48 hours & 34 days to 3 months \\
\hline${ }^{2}$ Czech Republic & Danger & Non-medical & No & 24 hours & 3 months \\
\hline${ }^{2}$ Lithuania & Danger & Non-medical & No & 48 hours & 1 month \\
\hline${ }^{2}$ Slovak Republic & Danger & Non-medical & No & 24 hours & 3 months \\
\hline${ }^{2}$ Poland & Danger & Non-medical & No & 48 hours & 10 days to 6 months \\
\hline
\end{tabular}

1 Salize \& Dressing (2004).

2 EUNOMIA project (Kallert et al, 2005).

that provided diagnostic data. The proportions of groups with other diagnoses, such as dementia, affective disorders or substance misuse, differ remarkably.

Information about the sociodemographic characteristics of involuntarily admitted patients is as scarce as information on psychopathological background. There seems to be an overrepresentation of male patients, which might serve as a rough indicator that danger is the prime consideration in involuntary placement, since men with mental illness reportedly are more likely than women to show dangerous behaviour (Salize \& Dressing, 2004). Several studies have confirmed that involuntary admission is more frequent among patients with an immigrant background than among the general population (Tolmac \& Hodes, 2004; Ali et al, 2007; Torrissen, 2007). In a 3-year prospective study in Norway looking at the characteristics of voluntary and involuntary psychiatric admissions of immigrants, Iversen et al (2011) concluded that involuntarily admitted immigrants more often have a diagnosis of schizophrenia and psychotic disorders than immigrant patients who are voluntarily admitted. However, for a valid comparison, the proportion of compulsorily admitted males should have been tested against the proportion of total admissions of males to psychiatric in-patient care in each country. Unfortunately, these data are not available.

\section{Conclusions}

Legal regulations as well as routine procedures for detaining people who are mentally ill differ considerably across Europe. Specification of the various national regulations presents an opportunity to harmonise national laws. However, there is limited evidence on which to recommend best practice, and this constitutes a major obstacle to any mutual European action. International epidemiological research in this field is needed for an evaluation of the effectiveness of different approaches. Diverse legal traditions, general attitudes towards people who are mentally ill, and the structure and the quality of mental healthcare systems or administrative procedures must be considered along with other factors when analysing outcomes from the different legal frameworks. It will be an important task to adapt legal frameworks in all countries, balancing patients' rights and interests against their need for and right to treatment.

The substantive and procedural safeguards suggested by the case law of the European Court of Human Rights (ECHR) will need to be addressed when drafting legislation providing for the detention of individuals on the grounds of mental disorder (Knapp et al, 2007). The MI Principles of the United Nations provide for the detention of individuals with a 'mental illness' in mental health facilities, and set out the conditions for detention, review of the decision and relevant procedural safeguards. On the other hand, commentators have raised concerns about the level of protection offered by the MI Principles regarding detention (UN Secretary-General, 2003) and a review of the Principles has been suggested. Internationally standardised and annually updated involuntary placement rates on a national level are fundamental to the evaluation of national as well as Europe-wide policies.

An important limitation of the present paper is that it does not include data from all European countries.

\section{References}

Ali, S., Dearman, S. P. \& McWilliam, C. (2007) Are Asians at greater risk of compulsory psychiatric admission than Caucasians in the acute general adult setting? Medicine, Science, and the Law, 47, 311-314. 
Appelbaum, P. S. (1997) Almost a revolution: an international perspective on the law of involuntary commitment. Journal of the American Academy of Psychiatry and the Law, 25, 135-147.

Darsow-Schutte, K. I. \& Muller, P. (2001) Number of hospitalizations according to German 'PsychKG' legislation has doubled in 10 years. Psychiatrische Praxis, 28, 226-229.

Dressing, H. \& Salize, H. J. (2004) Compulsory admission of mentally ill patients in European Union member states. Social Psychiatry and Psychiatric Epidemiology, 39, 797-803.

Gostin, L. O. (2000) Human rights of persons with mental disabilities. The European Convention on Human Rights. International Journal of Law and Psychiatry, 23, 125-59.

Iversen, V. C., Berg, J. E., Smavik, R., et al (2011) Clinical differences between immigrants voluntarily and involuntarily admitted to acute psychiatric units: a 3-year prospective study. Journal of Psychiatric and Mental Health Nursing (in press).

Kallert, T. W., Glockner, M., Onchev, G., et al (2005) The EUNOMIA project on coercion in psychiatry: study design and preliminary data. World Psychiatry, 4, 168-172.

Knapp, M., McDaid, D., Mossialos, E., et al (2007) Mental Health Policy and Practice. European Observatory on Health Systems and Policies Series. Open University Press.
Riecher-Rossler, A. \& Rossler, W. (1993) Compulsory admission of psychiatric patients - an international comparison. Acta Psychiatrica Scandinavica, 87, 231-236.

Salize, H. J. \& Dressing, H. (2004) Epidemiology of involuntary placement of mentally ill people across the European Union. British Journal of Psychiatry, 184, 163-168.

Swanson, J. W., Holzer, C. E., 3rd, Ganju, V. K., et al (1990) Violence and psychiatric disorder in the community: evidence from the Epidemiologic Catchment Area surveys. Hospital and Community Psychiatry, 41, 761-770.

Tolmac, J. \& Hodes, M. (2004) Ethnic variation among adolescent psychiatric in-patients with psychotic disorders. British Journal of Psychiatry, 184, 428-431

Torrissen, T. (2007) Tvangsinnleggelser i en akuttpsykiatrisk post. [Involuntary admissions to an acute psychiatric ward.] Tidsskrift for den Norske legeforening, 127, 2086-2089.

UN Secretary-General (2003) Progress of efforts to ensure the full recognition and enjoyment of the human rights of persons with disabilities - report of the Secretary-General (A/58/181). Available at http://www. un.org/disabilities/default.asp?id=148 (accessed June 2011).

\title{
Naturalistic study of crisis referrals to an Irish community adult mental health service
}

\author{
Tunde Apantaku-Olajide ${ }^{1}$ MBBS, Bobby P. Smyth ${ }^{2}$ MRCPsych \\ and Pat Gibbons ${ }^{3}$ MRCPsych
}

\begin{abstract}
${ }^{1}$ Registrar in Addiction Psychiatry, Youth Drug and Alcohol Service (YoDA), Dublin, Ireland, email tunde.apantaku@hse.ie; ${ }^{2}$ Consultant Child and Adolescent Psychiatrist in Substance Use, HSE Addiction Services, Cherry Orchard Hospital, Dublin, Ireland; ${ }^{3}$ Consultant in General Adult Psychiatry, Naas General Hospital, Kildare, Ireland
\end{abstract}

Thens here is no agreed definition of a mental health crisis; however, a useful one is 'a situation where mental health has deteriorated to an extent that the user is likely to be at risk of harm to self or others and is in need of urgent intensive specialist support and treatment' (Minghella et al, 1998). Community-based care is the primary model of specialist mental healthcare in Ireland (Government of Ireland, 2006a). When clinically indicated, a patient with mental health crisis is referred to the community mental health team (CMHT) for an urgent assessment.

Most data available on the relationships between patients' explanatory variables, crisis referrals and urgent demands in mental healthcare are from international studies, which have highlighted the relevance of acute psychosis, marked affective symptoms, risk to self or others, and lack of social support (Abas et al, 2003; Johnson et al, 2005; Cotton et al, 2007). Although urgent referrals are for people in crisis, the crisis may be psychosocial in nature (Spurrell et al, 2003). Therefore, understanding mental health crisis and patients' explanatory variables within a sociocultural context is necessary for a more targeted referral system that offers optimal interventions and the appropriate use of services.

The study reported here explored the demographic and clinical characteristics of patients referred to an Irish CMHT and sought to identify the key differences between crisis and scheduled referrals.

\section{Method}

This was a retrospective analysis of the clinical records of all people who attended a CMHT within the 12 months 1 January-31 December 2008. This CMHT provides services to a well-defined catchment area in the North Kildare area of Ireland, a suburban and rural population of approximately 35000 (Government of Ireland, 2006b). The team receives referrals from 22 general practices, other CMHTs and a local general hospital emergency department. The team provides home-based assessments and treatment of acute mental illness, together with out-patient care, day hospital and inpatient care at the local general hospital where necessary.

A standard form is used for all referrals made to the team. This requires the referrer to indicate the perceived urgency of assessment. The completed form is faxed to the mental health centre office. In addition, the referrer is required to alert the home care team to crisis referrals using a designated mobile telephone number during office hours. Crisis referrals are reviewed by telephone with the referrer and an appointment offered depending on the degree of urgency as determined by the referrer, with same-day assessments available during weekday working hours. The waiting period for routine referrals is usually $7-14$ days.

Demographic data collected included age, gender and marital status, past psychiatric illness and source of referral. 